\title{
Metafísica y sentido común. La deconstrucción de la matriz heteronormativa en el pensamiento de Judith Butler
}

Metaphysics and common sense. The deconstruction of the heteronormative matrix in Judith Butler's thought

\author{
Alejandro Chuca alejandrochuca@gmail.com \\ https://orcid.org/0000-0002-1422-2638
}

Instituto de Investigaciones Gino Germani; Facultad de Ciencias Sociales; Universidad de

Buenos Aires 


\section{Resumen}

El objetivo de este trabajo es dar cuenta de la matriz heteronormativa que produce la exclusión que sufren todos aquellos que asumen identidades de género por fuera del binarismo hombremujer. Para ello primero se dará cuenta de la postura posfeminista que desarrolla Butler, demostrando en un segundo momento las influencias que le permitieron a la autora norteamericana dar un salto por sobre los planteos del feminismo más bien cercanos a un modelo sustancialista. Por esa razón haremos especial hincapié en la cuestión de la metafísica de la sustancia que domina el pensamiento occidental, exponiendo la nueva forma que elabora Butler para pensar la realidad social y los sujetos. Luego argumentaremos a favor del vínculo existente entre metafísica y sentido común, para demostrar su efectividad cotidiana a la hora de reproducir la matriz heteronormativa. Para finalizar expondremos los modos tanto macro como microsociológicos en que funciona la producción de identidades de género.

Palabras clave: Judith Butler; genero; teoría queer; metafísica; sentido común.

\section{Abstract}

The objective of this paper is to account for the heteronormative matrix that produces the exclusion suffered by all those who assume gender identities outside of male-female binarism. The post-feminist posture developed by Butler will be exposed, demonstrating in a second moment the influences that allowed the north american author to take a leap over feminism's approaches rather close to a substantialist model. For that reason, we will put special emphasis on the question of the metaphysics of the substance that dominates western thought, exposing the new way that Butler elaborates to think about social reality and subjects. Then we argue in favor of the link between metaphysics and common sense, to demonstrate its effectiveness in everyday reproduce of the heteronormative matrix. Finally, we will expose the macro and microsociological modes in which the production of gender identities works.

Kewwords: Judith Butler; gender; queer theory; metaphysics; common sense. 
A principios de los años noventa aparece en Estados Unidos una perspectiva nueva en los estudios de género que se denominó teoría queer, en la que Judith Butler se destaca como una de las autoras más representativas de esta línea teórica, que busca poner en cuestión el carácter "natural" y por lo tanto inevitable de lo que se llamó la matriz heteronormativa. La cual constituye un modo binario de entender y clasificar el género limitándolo a lo "masculino" y a lo "femenino".

Si bien Butler inicio su militancia política y teórica en el feminismo ella no se considera una feminista. Sino que plantea que su pensamiento se coloca en lo que ella denomina el posfeminismo. Butler supone que el feminismo va de la mano del modelo de la ilustración que limita, debido al tipo de pensamiento metafísico que sostiene, el modo de entender el género.

Es importante dar cuenta de la crítica que realiza Butler al feminismo para ir comprendiendo por un lado el desprendimiento del feminismo que lleva la autora y por otro lado exponer sintéticamente las influencias de los pensadores que le permitieron proponer un pensamiento posfeminista.

A principios de los noventa, cuando Butler interviene en el debate feminista, este movimiento se dividía fundamentalmente en dos grandes corrientes. Las que presuponían que el género era la interpretación cultural de un sexo natural, y por otro lado las que insistían en que el sexo introduce una diferencia natural inevitable (Femenías, 2003). Pero Butler plantea que entender al sexo como la base material o natural del género, es el efecto de un régimen de producción binario que posibilita ver al sexo como algo natural, ajeno a las categorías y producciones culturales existentes. Desencializar el sexo, como veremos en profundidad más adelante, desestabilizó la idea de mujer que el feminismo daba por hecho y sobre la cual se montaban los reclamos políticos. Empezar a hacer notar por parte de Butler que el sexo natural no existe como tal, por lo tanto tampoco existe la mujer como tal, produjo una efecto de apertura a integrar nuevas minorías sexual, es que al igual o más que las mujeres sufrían y sufren del rechazo social. En efecto, continuar afirmando la existencia de las mujeres como oposición al género dominante los hombres, en su bien intencionado intento de emanciparlas, termina sometiendo a las minorías sexuales a la exclusión por no poder ser parte del esquema binario hombre-mujer.

En este punto es importante remarcar que para Butler la problemática de género además de ser un problema teórico, es sobre todo y fundamentalmente, una postura ético-política que 
busca abrir a nuevas formas de ser. Es en ese sentido que la dualidad mujer-hombre que plantea el feminismo, cierra y excluye las posibilidades de vidas diversas que se salten la matriz binaria heteronormativa.

Contener multitudes. Las influencias de otros pensadores en el pensamiento de Butler

Butler está influenciada por, por lo menos, cinco líneas teóricas que nos interesa destacar. Una de ellas es la lectura de Luce Irigaray (1982), que retomando a Lacan plantea el modo falologocéntrico que tiene el lenguaje, que centra al orden simbólico alrededor de lo masculino. En donde cualquier sujeto que pretenda constituirse como tal, sería necesariamente un sujeto varón.

La segunda lectura que influencia a Butler es la de Adrianne Rich, quien afirma que toda heterosexualidad es un disciplinamiento obligatorio o compulsivo. Ya que la base biológica en tanto tal no se define en cuanto a la elección del objeto sexual, sino a posteriori a partir de disciplinamientos culturales.

El tercer pensador que influyó fuertemente en ella es Michel Foucault. De Foucault va a retomar la noción de disciplinamiento, como a su vez la idea de que lo que hay son cuerpos que ya están construidos culturalmente, lo cual no permite dar cuenta de un sexo natural. Porque cualquier acercamiento a un cuerpo es ya siempre un acercamiento a través de la cultura y de la lengua. No hay, de este modo, posibilidad de un acceso a un cuerpo originario, puro e independiente de las relaciones de poder. Cualquier cuerpo es siempre un cuerpo construido dentro de relaciones sociales existentes. Por esta razón Butler utilizará de modo indistinto los términos sexo o género como si fueran sinónimos, ya que considera errónea la distinción entre género y sexo (Femenías, 2003).

El cuarto pensador que influencio fuertemente a Butler fue Jacques Derrida. Muy leído en EE. UU. donde tuvo en un principio una recepción fuerte, implica una influencia determinante en el pensamiento de la autora norteamericana a la hora de pensar por sobre las dualidades recurrentes de la metafísica occidental. En el ámbito de género, gracias a textos como De la gramatología (1998), Butler comienza por deconstruir la dualidad que distinguía entre género y 
sexo, siendo el género considerado un producto cultural que se posa sobre el sexo como cuerpo natural. La dualidad genero/sexo es solidaria de las dualidades cultura/naturaleza, espiritual/material, mente/cuerpo, etc. que continuaban en el ámbito de los estudios de género con las recaídas metafísicas del modo de pensar occidental que se inician, como indica Derrida, con Platón y su dualismo ontológico.

La quinta línea de pensamiento que influencia a Butler tiene que ver más bien con una tradición que inicia la sociología y la antropología. Esta tradición se podría indicar que nace con la crítica de Marx (1985) a la antropología filosófica de Feuerbach y continúa hasta nuestros días en la obra de Pierre Bourdieu. Para Bourdieu la sociología busca develar "la contingencia allí donde se quiere ver la necesidad o la naturaleza" (2000: 26) cuando al historizarla logra desnaturalizar las desigualdades que se quieren hacer pasar como inherentes a la condición humana (1996: 48; 2006: 103). El movimiento de desnaturalización que realizará Butler es constante y es justamente uno de los puntos centrales de su labor teórica que le permitirá salir del siempre limitante y autoritario argumento de "lo natural".

Para Butler vivimos procesos de disciplinamiento que nos constituyen como cuerpos deseantes de lo que no somos, es decir, del "sexo opuesto" dentro una matriz binaria. Por lo tanto, se han ido construyendo varones y mujeres a través de dispositivos de disciplinamiento que intentan satisfacer ciertos modelos normativos. En este planteo que elabora Butler no tiene ningún lugar la naturaleza. Ya que considera que no es posible observar ni observarnos desde un lugar acultural, aséptico, en donde se pueda definitivamente ver la naturaleza de nuestro ser. En este punto Butler es radical ya que afirma que no existe el cuerpo natural. Todo cuerpo es inevitablemente un cuerpo cultural en donde se inscriben la historia, las relaciones sociales, el poder, etcétera.

En efecto, Butler continúa la línea del constructivismo que plantea como premisa incuestionable el carácter constructivo de la realidad. Ya que despeja toda posibilidad alguna de plantear una naturaleza, esencia o sustancia previa que venga a determinar o influenciar el comportamiento y modo de ser de los sujetos. Para Butler estas afirmaciones son sumamente peligrosas y afectan de modo directo los objetivos ético-políticos por los que cualquier minoría sexual pueda luchar. El efecto de hablar de "lo natural" o "lo esencial" es el de crear un orden que limita y sutura toda posibilidad de modificación. El argumento de la naturaleza es sin dudas prescriptivo y genera y acompaña el disciplinamiento de la matriz binaria y heteronormativa.

Es como consecuencia de este razonamiento que Butler se va a alejar del feminismo, dando origen a planteos posfeministas. El movimiento feminista planteaba la existencia de la mujer

Question, Vol. 1, N. ${ }^{\circ}$ 63, julio-septiembre 2019. ISSN 1669-6581

Instituto de Investigaciones en Comunicación | Facultad de Periodismo y Comunicación Social | Universidad Nacional de La Plata 
como categoría original y universal. Si bien, lógicamente, Butler reconoce el dominio masculino por sobre el femenino, limitar el análisis a esa dualidad lo empobrece y deja por fuera otros modos de construir subjetividades. En efecto, la categoría de mujeres entra en duda y deja de tener su identidad armada en contraposición a la categoría de hombre, ya que insistir en el término mujer y hombre implicaría reproducir la matriz binaria, que reproduce a su vez la lógica de lo natural o esencial, que la pensadora norteamericana quiere deconstruir.

Las problemáticas cotidianas son también un problema metafísico. La crítica a la metafísica a la sustancia de género. La influencia de Nietzsche

Uno de los elementos más interesantes que plantea Butler a nuestro entender es la vinculación que permite establecer entre el dolor personal y social y la metafísica. Generalmente se puede considerar a la metafísica como una mera abstracción alejada de la vida cotidiana de los seres humanos que no tendría ningún interés especial para estos, siendo sus efectos tan solo algo que debería preocupar a los filósofos especializados en ella. Pero Butler demuestra claramente que la cotidianidad del dolor de los disidentes de género, tiene como una de sus causas la forma de pensar que se expande sobre occidente que no puede observar como posible, ni lógico ni normal una identidad de género múltiple y en constante devenir.

La lista, evidentemente no exhaustiva, de influencias que nombramos anteriormente faltaba el nombre de un autor, que si bien se cuela a través de las lecturas de Foucault y Derrida, su influencia es más bien directa. Este es el caso de Friedrich Nietzsche. Quien ha permitido a Butler dar cuenta de la metafísica de la sustancia y su feroz crítica. Para no extendernos en un tema complejo y rico como es el problema de la metafísica de la sustancia, es mejor reproducir la cita que Butler retoma de Haar que expresa sintéticamente el núcleo del problema:

La destrucción de la lógica mediante su genealogía implica además la desaparición de las categorías psicológicas basadas en esta lógica. Todas las categorías psicológicas (el yo, el individuo, la persona) proceden de la ilusión de identidad sustancial. Pero esta ilusión regresa básicamente a una superstición que engaña no sólo al sentido común, sino también a los filósofos, es decir, la creencia en el lenguaje y, más concretamente, en la verdad de las categorías gramaticales. La gramática (la estructura de sujeto y predicado) sugirió la certeza de Descartes de que «yo» es el sujeto de «pienso», cuando más bien son los Question, Vol. 1, N. ${ }^{\circ} 63$, julio-septiembre 2019. ISSN 1669-6581 
pensamientos los que vienen a «mi»: en el fondo la fe en la gramática solamente comunica la voluntad de ser la causa de los pensamientos propios. El sujeto, el yo, el individuo son tan sólo falsos conceptos, pues convierten las unidades ficticias en sustancias cuyo origen es exclusivamente una realidad lingüística (Butler, 2006: 78).

Como expresa Haar siguiendo a Nietzsche, el truco que realiza la gramática sobre el sentido común es el de pensar a los sujetos como los propietarios de esos pensamiento que supuestamente ellos tienen y que bajo el dominio de su voluntad realizarían. La creencia ingenua en la gramática produce una ilusión de sustancia en los sujetos, reproduciendo la ficción de que se mantienen siempre idénticos a sí mismos. En este caso el "yo", el nombre propio, funcionan como amarras fijas para una identidad que es esa y siempre esa. Lo fundamental es que esto, como dice Haar, no es solo una ilusión en la que cayeron los filósofos como Descartes, sino que perdura y extiende su existencia en el sentido común de cualquier sujeto. Los cuales, sin siquiera leer a Descartes o algún filosofo con el mismo pensamiento, continúan y afirman la metafísica de la sustancia al creerse ellos mismo una identidad cerrada, finalizada e inmodificable en su esencia.

En este sentido, si para la metafísica de la sustancia el sujeto es un sustantivo, Butler, continuando con el juego gramatical, propone una ontología de los gerundios:

Sugiero, como más apropiado, un vocabulario que resista la sustancia metafísica de las formaciones sujeto-verbo y, en su lugar, se apoye en una ontología de los gerundios. (...) Como materialidad intencionadamente organizada, el cuerpo es siempre una encarnación de posibilidades a la vez condicionadas y circunscritas por la convención histórica. En otras palabras el cuerpo es una situación histórica, como lo declara Beauvoir, y es una manera de ir haciendo, dramatizando y reproduciendo una situación histórica (1988: 299).

"Haciendo", "dramatizando", "reproduciendo" implican una apropiación de la gramática (ya que por fuera de ella no hay nada y tampoco tenemos por ahora otra gramática para utilizar) que evita los problemas que otro uso de ésta pueden llevar a una metafísica de la sustancia. Butler opta por pensar al género y al cuerpo como una continua formación que, como indican los gerundios, son acciones que se extienden durante un lapso de tiempo. En este sentido, se 
puede afirmar, que la identidad de género no es un sustantivo fijo y finalizado, sino un verbo, una acción que se extiende durante la vida de los sujetos y que no termina sino con su muerte.

En conjunto con esta ontología de los gerundios, Butler agrega una ontología de la relación. Si bien ninguna de estas dos ontologías están muy desarrolladas por la pensadora norteamericana, nos parece fundamental resaltarlas porque implica, aunque quizás sea un aspecto menos remarcado de su trabajo, un aporte fundamental para su crítica de la matriz heteronormativa. Dice Butler:

\begin{abstract}
Esta perspectiva relacional o contextual señala que lo que "es" la persona y, de hecho, lo que "es" el género siempre es relativo a las relaciones construidas en las que se establece. Como un fenómeno variable y contextual, el género no designa a un ser sustantivo, sino a punto de unión relativo entre conjuntos de relaciones culturales e históricas específicas (2006: 61).
\end{abstract}

En este punto Butler continua una línea ontológica que inauguro Marx que se sintetiza muy bien en una de sus tesis sobre Feuerbach: "La esencia humana no es algo abstracto e inmanente a cada individuo. La esencia humana es, en su realidad, el conjunto de las relaciones". En esta famosa frase Marx pone en jaque la idea de esencia, en un sentido muy similar al que luego realiza Butler. Para el pensador alemán no existe tal esencia, sino que ésta es el conjunto de las relaciones, determinadas por el contexto en el que los sujetos se desarrollan y que, por sobre todas las cosas, es profundamente histórica por lo tanto varia constantemente. En este punto es que la ontología de la relación, se une con la ontología de los gerundios, ya que conviven en la idea de evitar la sustancialización apostando al devenir histórico y relacional. Ambas ontologías a su vez, pero sobre todo la ontología de la relación, ponen el acento en que la vida de los seres humanos es profundamente relacional. Lo cual para Butler determina el proceso de formación de la identidad de género, que, como veremos más adelante, no es nunca un proceso solitario e individual, sino que está atravesado por múltiples y diversas relaciones.

Es importante destacar que Butler, por más que ponga mucho énfasis en la construcción cultural de la identidad de los sujetos, no por ello plantea la idea de que cada sujeto construye su propia identidad desde una pura y absoluta voluntad individual. El sujeto es un sujeto sujetado, al que las normas, la historia y las relaciones sociales lo exceden y lo influencian en 
su modo de actuar. Pero no por ello el sujeto está plenamente determinado por las normas sociales. La incompletitud en la determinación posibilita la desviación hacia nuevas formas.

La máquina de excluir: matriz binaria, heteronormatividad y la producción de vidas invivibles

El objetivo de desarmar la matriz binaria está motivado a su vez por volver posible las vidas de las "sexualidades periféricas", que son aquellas que no se ajustan a los parámetros dominantes, por lo cual sufren de rechazo social, discriminación y estigma. Es en este punto que el pensamiento de Butler tiene una dimensión ética fundamental, que busca abrir el juego para posibilitar nuevas vidas.

Butler plantea que algunos humanos son reconocidos como menos humanos y que dicha forma de vida, sin el reconocimiento necesario, conduce a una vida inviable. Según ella, si parte del deseo lo que busca es obtener reconocimiento, el género, en tanto está animado por el deseo, buscará también el reconocimiento de los demás.

\begin{abstract}
Pero si los proyectos de reconocimiento que se encuentran a nuestra disposición son aquellos que "deshacen" a la persona al conferirle reconocimiento, o que la "deshacen" al negarle reconocimiento, entonces el reconocimiento se convierte en una sede del poder mediante la cual se produce lo humano de forma diferencial. Esto significa que en la medida en que el deseo está implicado en las normas sociales, se encuentra ligado con la cuestión del poder y con el problema de quién reúne los requisitos de lo que se reconoce como humano y quién no. ¿Habrá un lugar para mi vida y será reconocible para los demás, de los cuales dependo para mi existencia social? (Butler, 2006: 15).
\end{abstract}

La palabra queer fue y es utilizada como un insulto hacia todas las formas "anormales" de la sexualidad. Invertida en su sentido, la palabra queer empieza a ser revalorizada, hasta el punto de dar nombre a las teorías de las que Butler es un fiel exponente. El movimiento queer, escapando a las esencializaciones identitarias, se define como un movimiento posidentitario 
(Preciado, 2012). En este sentido el movimiento político y teórico queer no es un movimiento de gays, ni de mujeres ni de transexuales, sino que es un movimiento de disidentes de género. De esta manera, la teoría de Butler busca crear las condiciones para que aquellos que asumen identidades de género diferentes a la matriz binaria, puedan obtener vidas vivibles a través del reconocimiento de su identidad como válida.

Butler sostiene que en la modernidad occidental, se ha establecido un régimen normativo con respecto a la sexualidad y el género que es la heteronormatividad. Dicho régimen define y establece cuales son las formas inteligibles y correctas de asumir identidades de géneros, castigando a todas aquellas que se desvíen de ellas. De esta manera solo existen dos modelos de identidades de género correctas: hombres y mujeres. Al interior de estos modelos, según plantea el discurso dominante, se debe dar una coherencia exacta entre género, deseo y práctica sexual. Por esta razón "los géneros 'inteligibles' son lo que de alguna manera instauran y mantienen relaciones de coherencia y continuidad entre sexo, genero, práctica sexual y deseo" (Butler, 2007: 73).

En el caso de que la relación entre esos componentes no se dé de la manera esperada, dicha identidad sexual es rechazada y considerada anormal, llegando, en determinados casos, a considerarla directamente como patológica. La posibilidad de que exista y se den discursos y acciones que califican a ciertas identidades como anormales, demuestran la cruel eficacia de la matriz heteronormativa.

Uno de los primeros pasos que Butler considera necesarios es el de dar cuenta que el régimen heterosexista se instaló en el sentido común de las sociedades modernas, a tal punto de plantearse como obvio, natural y originario el modo binario de entender la sexualidad.

Identificar esta violencia era difícil porque el género era algo que se daba por sentado y que al mismo tiempo se vigilaba terminantemente. Se presuponía que era una expresión natural del sexo o una constante natural que ninguna acción humana era capaz de modificar (Butler, 2007: 24).

Por esas razones es que el objetivo central del pensamiento de Butler es el de desnaturalizar y deconstruir el régimen binario y heteronormativo, para poder aplacar sus efectos violentos. 
El empeño obstinado de este texto por 'desnaturalizar' el género tiene su origen el deseo intenso de contrarrestar la violencia normativa que conllevan las morfologías ideales del sexo, así como eliminar las suposiciones dominantes acerca de la heterosexualidad natural o presunta que se basan en los discursos ordinarios y académicos acerca de la heterosexualidad, obedece a un deseo de vivir, de hacer la vida posible, y de replantear lo posible en cuanto tal (2009: 24).

La destrucción de este régimen va a ampliar el marco de lo pensable y lo posible. En ese sentido el régimen heterosexista es limitante, reduciendo la posibilidad de desplegar mejores vidas para las minorías sexuales.

Para lograr este objetivo se necesitan de varias dimensiones. Por un lado estará, lógicamente, la dimensión de la lucha ético-política, pero por otro lado, aunque parezca "abstracta" o supuestamente ajena a la cotidianidad, estará la crítica a la metafísica de la sustancia que permite sostener el discurso heteronormativo.

Metafísica y sentido común. Esa intimidad

En este punto Butler demuestra bien que la metafísica no es algo lejano, para intelectuales y sin efectos para la vida "mundana" de los sujetos. Sino que los determinados tipos de pensamiento metafísicos están profundamente arraigados al sentido común que se repite en las calles.

En consonancia con lo anterior, Butler observa que la matriz binaria es solidaria de dicha metafísica ya que plantea la existencia de dos sustancias estables, los hombres y las mujeres, que son los únicos modos en que puede expresarse el ser humano. En este sentido los géneros no serían más que la expresión de un identidad preexistente, a priori y originaria que dará por fruto a los hombres o a las mujeres como únicas posibilidades y manifestaciones del ser en tanto ser humano. En efecto, la esencia o sustancia, o la naturaleza se convertirían en un destino inevitable. Son proyectos ineludibles, ajenos a la historia y las características sociales. 
La teoría popular implícita de los actos y los gestos como expresivos del género sugiere que el género mismo es algo previo a los varios actos, posturas y gestos mediante los cuales es dramatizado y conocido; de hecho, el género aparece para la imaginación popular como un núcleo sustancial que podría ser entendido como un correlato psíquico o espiritual del sexo biológico (Butler, 1988: 528).

En este punto es importante detenerse. A simple vista puede ser difícil ver la importancia de la metafísica en la construcción del sentido común y la opinión pública. Pero, algo fundamental que hace Butler, es demostrar como un dolor personal, intimo, tiene un correlato directo con la metafísica. Un dolor personal también es una cuestión metafísica. En este punto es en donde se engancha la preocupación cotidiana del dolor que sufrieron y sufren los "disidentes de género" al no entrar en ningún casillero de la estructura metafísica. La matriz heteronormativa y el régimen binario están atravesado por una metafísica que los posibilita y que retroalimentan.

La metafísica, desde la antigua Grecia a hoy, nunca se limitó al mero conocimiento del ser. Sino que siempre estuvo al servicio de construir formas de la "vida buena", buscando dar cuenta de las normas sociales del comportamiento correcto. A partir de conocer el verdadero ser de las cosas, la forma esencial de las cosas, describe cómo estás deberían actuar. En este sentido la metafísica no es solo una forma de describir el mundo, sino que es una forma de prescribirlo. De darle límites, de justificar acciones. En efecto, ninguna metafísica es inocente. Lo que se esconde bajo la forma de una descripción del ser de las cosas, tiene efectos limitantes sobre la vida de los sujetos. Entonces si la supuesta esencia o naturaleza de los seres humanos es ser hombre o ser mujeres, la posibilidad de trasgredir esas únicas dos opciones es finalmente considerada como un acto contra natura, como una imposibilidad estructural, una locura patológica que atenta contra la "verdad" de las cosas.

El régimen heterosexista en sus niveles macro y micro sociológicos. Una distinción analítica 
El régimen heterosexista actúa de dos formas: por un lado como un fenómeno macro sociológico y por otro lado como un fenómeno microsociológico. Si bien uno puede hacer esta distinción, no significa que sean acciones que corran por separado. Es decir, dentro del nivel macro sociológico se puede colocar a la metafísica sustancialista y binaria que describíamos antes. Pero esto no equivale a decir que esta estructura objetiva de pensamiento que es la metafísica no se reproduzca en cada comentario, charla o gesto micro que puede aparecer en cada instante de la vida cotidiana. Sin embargo y a pesar de lo ficcional de la distinción (¿cuál no lo es?), la distinción macro-micro puede dar luz sobre el análisis de cómo se reproduce el régimen heterosexista.

Lo fundamental que quiere remarcar Butler es que a nivel macro existe un sistema de heterosexualidad obligatoria, que funciona, así como lo describió Foucault para los dispositivos, de una manera disciplinaria. Este nivel implica tener en cuenta todas las estructura objetivas, sobre todo las institucionales, que obligan a los sujetos a definirse como hombres o mujeres, como puede ser el caso de declarar su sexo durante un trámite de registro en un Estado que solo ofrece dos opciones para ubicarse.

Un análisis estructural, no puede olvidar los aspectos micro que tiene la reproducción del régimen binario. En caso de pensar a la heterosexualidad normativa como algo que se inscribe en los cuerpos de los sujetos sin más, implicará considerar a estos como meros receptores pasivos. Para evitar esto es importante pensar el modo continuo en el que los sujetos van constituyéndose unos a otros de manera mundana y que permite la producción y reproducción de las identidades de género establecidas. En esta línea y en contra de la metafísica de la sustancia que tiende a estabilizar y congelar las identidades, es que Butler piensa a los sujetos y a la realidad social de un modo continuamente naciente, en donde "no hay ningún "ser" detrás del hacer, del actuar, del devenir; el agente ha sido añadido ficticiamente la hacer, el hacer es todo" (Butler, 2007: 85). De este modo la subjetividad no es un sustantivo definitivo, sino que es un continuo hacerse que va haciendo al sujeto lo que es en cada acto de su cotidianidad. Debido a que no hay esencia, ni sustancia ni naturaleza que destine y/o prefigure el destino de los sujetos, estos quedan librados a los actos históricos y cotidianos que van haciendo de ellos lo que son.

De este planteo se extrae la importancia que tienen los actos performativos en la constitución del género en la teoría de Butler. En su concepción performativa del género, Butler afirma que éste se constituye en la repetición de gestos, posturas, movimientos, acciones, etcétera, que tienen un efecto constructivo sobre la identidad. La repetición de estas acciones produce una 
estilización del cuerpo, que se sedimentan en la corporalidad de los sujetos y los hacen asumir ciertos modos y estilos con tanta eficacia que parecen como originarios de una interioridad anterior y esencial. Este modo generalizado y aceptado socialmente de construir solo dos identidades de género, producen al nivel del sentido común, una sensación de sustancia que tiende a naturalizar lo performativo.

\begin{abstract}
El cuerpo deviene su género a través de una serie de actos que son renovados, revisados y consolidados a través del tiempo (...) debe intentarse reconcebir el gendered body como el legado de actos sedimentados antes que como una estructura predeterminada o forcluida, una esencia o hecho, ya sea natural, cultural o lingüística (Butler, 1988: 523.)
\end{abstract}

Es en este punto justamente en donde se entrelazan de manera profunda la metafísica de la sustancia como momento "estructural" y la performatividad de la constitución del género como momento "subjetivo" que en su mundanidad también termina reproduciendo determinado tipo de pensamiento metafísico. Como dice Butler, "la apariencia de sustancia es exactamente eso, una identidad construida, una realización performativa en la que el público social mundano, incluidos los mismos actores, llega a creer y actuar en el modo de la creencia" (2007: 274). En este sentido la repetición cotidiana se entrelaza solidariamente con la reproducción de una metafísica de la sustancia ya que los propios sujetos son los que se exigen y exigen a los demás acciones que entren en relación con su "naturaleza original y estable" de hombre o de mujer. Lo cual establece un límite de inteligibilidad para poder pensarse e imaginarse como un hacerse continúo. La metafísica de la sustancia, que está vinculada y habita cómodamente el sentido común, restringe lo pensable y lo realizable de tal modo que limita, no solo los nuevos modos de vida, sino también la posibilidad de por lo menos pensarlos e imaginarlos.

En este punto es importante no tender a cargar las tintas sobre los aspectos estructurales y objetivos, que pueden llevar a pensar que el pensamiento de Butler es un pensamiento que le quita al sujeto su espacio de acción, convirtiendo a su cuerpo en un mero recipiente sin vida que acepta y acoge estructuras desprovistas de sujetos. Porque el problema de caer en un estructuralismo es el de pensar a los sujetos como meros tontos culturales que aceptan sin más los mandatos. Pero a su vez también el de pensar que esas estructuras no son "humanas, demasiado humanas" como para que no sean modificables, históricas y lo suficientemente políticas de modo tal que sea imposible o muy difícil que no devengan otras. En este nivel el 
problema del estructuralismo no es la existencia de una estructura en las sociedades que exceda a los sujetos, cosa que es muy difícil negar, sino el modo en que se piensa esa estructura como un férreo esqueleto metálico que no acepta ningún tipo de plasticidad.

Un análisis estrictamente estructural sobre las problemáticas de género no podría explicar, por ejemplo, los cambios positivos que se dieron en nuestro país en los últimos años. Del mismo modo que las subjetividades se construyen día a día y están en constante producción, también ocurre lo mismo con los elementos "objetivos" que existen en la matriz binaria. En este sentido el pensamiento de Butler rescata el proyecto ético-político que subyace en su teoría, que busca modificar las condiciones de vida de las minorías sexuales para posibilitar ámbitos más hospitalarios con las diferencias. Plantear la plasticidad de las matriz heteronormativa y binaria, implica afirmar el poder de acción político de los sujetos que buscan y desean transformar dicha realidad social. El hecho que la reproducción de la matriz heteronormativa sea una repetición no implica una repetición en términos de la continuidad de lo mismo en su estado idéntico. Debido a que en la repetición no es posible repetir lo mismo, sino que en esa repetición siempre va introduciendo desplazamientos que permiten, entre otras cosas, la historia de las sociedades. En esta repetición e imitación de los ideales de géneros es donde ocurre la diferencia. Como expresa Butler tanto la masculinidad como la feminidad son "sitios ontológicos fundamentalmente inhabitables" (2007: 284).

En efecto, toda construcción de una identidad en tanto hombre o mujer es siempre una imitación fracasada que nunca logra coincidir con su modelo, que son "normas fantasmáticas, imposible de personificar" (2007: 274). En esa imposibilidad, en ese fracaso social, que es personificar el género como lo "exigirían" los ideales normativos, es que estos ideales se van corriendo por resultar inhabitables. Dicha imposibilidad permite deslices y nuevas configuraciones que van filtrándose y dando lugar a nuevos modos de ser. En ese intento de ir acercándose al ideal, muchos logran representarlo en gran parte pero aun así producen creaciones que no permiten una igualdad sin más con el modelo. En efecto, se pueden observar casos de mujeres muy "feminizadas" que tienen gustos "masculinos" por los deportes, como es el caso del futbol, que aun realizando una actividad históricamente reducida a lo masculino, practican el deporte sin por ello dejar de satisfacer los otros requerimientos exigidos a una mujer. Con este ejemplo se demuestra que la imposibilidad del ideal permite aberturas ya que no puede establecer límites infranqueables, da origen a pequeñas "desviaciones" que en su producción y reproducción van socavando ese ideal. Ya que, continuando con el ejemplo, luego que las mujeres practiquen de modo indiscutido futbol, también se abre el juego a que se 
introduzcan en otros mundos masculinos como puede ser el de asumir trabajos históricamente considerados para hombres.

El modo en que la matriz heteronormativa produce limitaciones no se limita a la forma en que produce subjetividades, sino también en el modo en que limita el campo de lo pensable y posible de los sujetos. La heteronormatividad es, siguiendo a Foucault, un modo del poder, pero es también un modo del saber. Como bien describió el pensador francés el poder y el saber suelen moverse en sincronía reforzándose el uno al otro. De este modo la matriz heteronormativa también produce limitaciones a la hora de pensar identidades alternativas. En efecto, es también una grilla de inteligibilidad que permite ver y/o ocultar los aspectos que no se ajustan a su grilla. Lo cual produce saber, al compás que produce sujetos, que van caracterizando de anormales o patológicos formas no previstas por dicho saber. Como sabemos este saber puede ser justamente saber científico, que como ocurrió y continúa ocurriendo, diagnostica casos de disidentes de género como desviaciones de la normalidad de la naturaleza humana.

\section{Conclusión}

Como fuimos remarcando a lo largo del trabajo, nos parece fundamental la articulación que logra Butler entre metafísica y sentido común. Para quienes habitamos lugares interdisciplinarios, este vínculo nos habilita a pensar y unir dos disciplinas vecinas pero alejadas: la filosofía y la sociología. Lógicamente la metafísica ha sido y es una de las ramas centrales de la filosofía, como así también lo es la preocupación por la producción del sentido común para la sociología. La sociología ha rechazado constantemente los planteos metafísicos al considerarlos como mera especulación sobre aspectos incomprobables empíricamente. Pero como demostramos durante nuestra exposición, la metafísica es un asunto social, que produce placeres y tristezas, reconocimiento y rechazo, porque no se encuentra lejana a la cotidianidad de ningún sujeto. La metafísica está, inevitablemente, en la calle. El campo de investigación que abre un pensamiento como el de Butler permite interconectar a la filosofía y a la sociología para ver cuáles son los modos de cómo el sentido común y la metafísica organizan el pensamiento de los sujetos y qué efectos estos producen en sus vidas. Para afirmar el peso 
específico de la metafísica en la vida social no es necesario volver a formulaciones idealistas que acepten sin más la eficacia de las ideas por sobre la materialidad. Tampoco es necesario, pensamos, mantener la dualidad materialismo-idealismo. Como es en el caso de la matriz heteronormativa, la metafísica de la sustancia está legitimando instituciones específicas que van disciplinando a los sujetos, convencidas de que estos deben tener una identidad fija y única. Este puede ser el caso de cada uno de los Estados existentes en la actualidad que les exigen a sus ciudadanos una identidad única y estable de la cual los registros gubernamentales tienen que dar cuenta. Como decía Foucault, exigir una identidad estable es una cosa de policías. Pero también, en la cabeza de esos policías, como de otros sujetos, está la firme convicción de que uno es una cosa sola y que su naturaleza es destino e identidad. ¿Qué tipo de metafísica subyace en las formas que tienen los Estados de nombrar a sus cuidadanos? ¿Cómo se nombran los ciudadanos entre sí? El documento de identidad, el nombre propio, son cotidianidades sustancializadoras. Pero por sobre todo existe el lenguaje, que como vimos con Nietzsche, produce a través de la gramática ficciones de individualidad y esencia que impiden pensar de otro modo. ¿Tiene sentido seguir diciendo "metafísica" a algo que supuestamente está más allá de la realidad física? ¿O no es acaso un DNI, un nombre propio, una forma de gesticular impuesta, la materialización limitante de un sistema de pensamiento?

\section{Bibliografía}

Bourdieu, P. y Passeron, J. (1996). La reproducción (segunda edición). México: Fontamara.

Bourdieu, P. (2006). Los herederos. Los estudiantes y la cultura (segunda edición). Buenos Aires: Siglo XXI.

Butler, J. (1988). Performative Acts and Gender Constitution: An Essay in Phenomenology and Feminist Theory. Theatre Journal, 40(4), 519-531.

Butler, J. (2006). Deshacer el género. Barcelona: Paidos.

Butler, J. (2007). El género en disputa. El feminismo y la subversión de la identidad. Buenos Aires: Paidós.

Derrida, J. (1998). De la gramatología. México: Siglo XXI. 
Femenías, M. L. (2003). Aproximación al pensamiento de Judith Butler: Conferencia impartida por María Luisa Femenías en Gijón. Recuperado de http://www.comadresfeministas.com/publicaciones/enlaweb/femenias.pdf

Irigaray, L. (1982). Ese sexo que no es uno. Madrid: Saltes.

Marx, K. (1985). La Ideología alemana. ( trad. W. Roces). Buenos Aires: Ediciones Pueblos Unidos.

Preciado, B. (2012). "Queer": historia de una palabra. Parole de queer. Recuperado de http://paroledequeer.blogspot.com/2012/04/queer-historia-de-una-palabra-por.html 